\title{
Processing of Words and Faces by Patients with Left and Right Temporal Lobe Epilepsy
}

\author{
ANDREW W. ELLIS, ${ }^{1}$ JONATHAN C. HILLAM, ${ }^{2}$ ALISTAIR GARDNO, ${ }^{2}$ \\ and JANICE KAY ${ }^{3}$ \\ 'Department of Psychology, University of York, UK \\ ${ }^{2}$ Neuro-psychiatric Unit and Special Centre for Epilepsy, Bootham Park Hospital, Tork \\ ${ }^{3}$ Department of Psychology, University of Exeter \\ Correspondence and reprint requests: Andrew W. Ellis, Department of Psychology, University of York, \\ Tork YO1 5DD, England.
}

\begin{abstract}
Tests of word and face processing were given to patients with complex partial epilepsy focussed on the left or right temporal lobe, and to non-epileptic control subjects. The left TLE group showed the greatest impairment on object naming and on reading tests, but the right TLE group also showed a lesser impairment relative to the normal control subjects on both tests. The right TLE group was selectively impaired on distinguishing famous from non-famous faces while the left TLE group was impaired at naming famous faces they had successfully recognized as familiar. There was no significant difference between the three groups on recognition memory for words. The implications of the results for theories of the role of the temporal lobes in word and face processing, and the possible neural mechanisms responsible for the deficits in TLE patients, are discussed.
\end{abstract}

\section{Introduction}

Surgical removal of temporal lobe structures has long been known to have consequences for cognitive performance which differ according to whether the left or right temporal lobe has been excised. Left temporal lobectomy impairs performance on verbal memory tasks, while right temporal lobectomy has been shown to impair complex visuo-spatial memory (e.g. Milner, 1958; Petrides and Milner, 1982). Memory impairments of this sort are commonly assumed to be a consequence of damage to the hippocampal complexes of the left or right hemispheres, but deficits following anterior temporal lobectomy are not restricted to tasks involving long-term recognition or recall memory. For example, left anterior temporal lobectomy has been shown to affect the perception of dichotically presented nonsense syllables (Berlin et al., 1972), while right anterior temporal lobectomy affects the ability to report the number of dots in briefly presented dot patterns (Kimura, 1963). Such results suggest cortical as well as subcortical impairments in temporal lobe epilepsy.

Several other studies have reported significant differences between left and right temporal lobe epilepsy (TLE) patients who have not undergone temporal lobectomy. Fedio and Mirsky (1969) compared the performance $0953-4180 / 91 / 040121+08 \$ 3.50 / 0 \quad$ (C) 1991 CNS (Clinical Neuroscience) Publishers 
of left TLE, right TLE and "centrencephalic" (generalized seizure) children aged 6 to 14 years and non-epileptic control subjects on a range of verbal and nonverbal tasks. The left TLE group were impaired on the learning and recall of word lists while the right TLE group were impaired on recall of random designs and the complex Rey-Osterrieth figure. Selective impairment on tests of verbal memory in patients with left TLE or visuo-spatial memory in patients with right TLE have since been reported in a number of studies (e.g. Lavadas et al., 1979; Mayeux et al., 1980; Mungas et al., 1985; Hermann et al., 1987).

The present study compares the performance of two groups of patients with left and right temporal lobe epilepsy with that of matched nonepileptic control subjects on four tests of verbal processing and two tests of face recognition. The verbal processing tasks were tests of grammatical (syntactic) processing, object name retrieval, word reading and recognition memory for words. Impairments of confrontation naming in left TLE patients have previously been reported by Mayeux et al. (1980), but impairments of syntactic processing have not, to the best of our knowledge, been reported.

The present study also investigated aspects of the recognition of familiar faces. As far as we are aware, face processing deficits have not been reported in temporal lobe epilepsy patients. The right hemisphere of the human brain appears to be the more specialized for many aspects face processing, though the capacity to put names to faces may be part of the left hemisphere's verbal ability (H. Ellis, 1983; Rhodes, 1986; Warrington and James, 1967). The prediction for the present study was that patients with right TLE might show a deficit in recognizing famous faces as familiar, while patients with left TLE might show a deficit in naming famous faces that would be associated with impairments on other verbal processing tasks.

\section{Method}

Subjects

The two patient groups and the non-epileptic control group each comprised 17 subjects (eight male, nine female) matched on age (left TLE group mean age 35.5 , s.d. $=12 \cdot 3$, range $18-53$; right TLE group mean age $31 \cdot 1$, s.d. $=12 \cdot 4$, range 17-54; non-epileptic controls mean age $33 \cdot 4$, s.d. $=14 \cdot 5$, range 22-60) and educational level. For the TLE patients, assignment to left or right temporal lobe focus group was on the basis of repeated 8-channel EEG recordings. The mean duration of epilepsy for the left TLE group was 11.8 years (range 2-40 years); the mean duration for the right TLE group was $15 \cdot 4$ years (range $0 \cdot 75-40$ years).

\section{Tests}

Graded Naming Test (McKenna and Warrington, 1983). The subject is required to name 30 object pictures of progressively increasing difficulty. 
National Adult Reading Test (NART) (Nelson, 1982). The subject is asked to read aloud 50 relatively uncommon words with irregular spellings (e.g. placebo; zealot).

Test for the Reception of Grammar (TROG) (Bishop, 1982). Subjects were administered part of a sentence-picture matching test which assesses syntactic knowledge, requiring an appreciation of such things as the distinction between active and passive sentences.

Warrington Recognition Memory Test: Words (Warrington, 1984). The subject is shown a sequence of 50 common four- to six-letter words for $3 \mathrm{sec}$ each and is asked to rate each word as "pleasant" or "unpleasant". The subject is then shown 50 pairs of words and is asked to choose which member of each pair was in the memory set.

Warrington Recognition Memory Test: Faces (Warrington, 1984). The subject is shown a sequence of 50 unfamiliar faces for 3 sec each and is asked to rate each face as "pleasant" or "unpleasant". The subject is then shown 50 pairs of words and is asked to choose which member of each pair was in the memory set.

Faces line-up. In this test the subject is shown a sequence of 40 faces $(20$ famous, 20 unknown in a random order). The subject is required first to say whether each face is familiar or unfamiliar. If familiar, the subject is asked what the famous person does (politician, film star, etc) and what his/her name is. This provides scores out of 40 on judgement of familiarity and out of 20 for providing the occupation and name for the famous faces.

\section{Results}

Analysis of variance was used to evaluate the significance of the overall effect of subject group on each measure. Where a significant effect was found, the Newman-Keuls post-hoc test was used to make pairwise comparisons between the groups. The means for each subject group on each test are shown in Table 1.

Graded Naming Test. The overall effect of groups was significant $(\mathrm{F}=20.56$, $\mathrm{df}=2,48, p<0.001)$. Post-hoc Newman-Keuls tests $(p<0.05)$ showed that the control group performed significantly better than both the left and the right TLE groups, but that the left TLE group was significantly worse than the right TLE group on object naming.

National Adult Reading Test. One of the left TLE group refused to attempt this test. An unequal cells analysis of variance found a significant effect of subject group $(\mathrm{F}=7 \cdot 31, \mathrm{df}=2,47, p<0.01)$. Post-hoc Newman-Keuls tests $(p<0.05)$ showed that the control group performed significantly better than both the left and the right TLE groups, but that the left TLE group was 
TABLE 1. Mean scores for left and right temporal lobe epilepsy patients and non-epileptic control subjects on tests of word and face processing

\begin{tabular}{|c|c|c|c|}
\hline & $\begin{array}{l}\text { Left temporal } \\
\text { lobe epilepsy }\end{array}$ & $\begin{array}{l}\text { Right temporal } \\
\text { lobe epilepsy }\end{array}$ & Controls \\
\hline $\begin{array}{l}\text { Graded Naming Test } \\
(\max . \text { score }=30)\end{array}$ & 14.95 & 18.57 & $24 \cdot 06$ \\
\hline $\begin{array}{l}\text { New Adult Reading Test (NART) } \\
(\max . \text { score }=50)\end{array}$ & $26 \cdot 81$ & $29 \cdot 76$ & $37 \cdot 12$ \\
\hline $\begin{array}{l}\text { Test for the Reception of Grammar } \\
\text { (TROG) } \\
\text { (max. score }=13 \text { ) }\end{array}$ & $10 \cdot 35$ & $10 \cdot 71$ & $12 \cdot 35$ \\
\hline $\begin{array}{l}\text { Warrington Recognition Memory Test } \\
\text { (Words) } \\
\text { (max. score }=50)\end{array}$ & $45 \cdot 71$ & $45 \cdot 76$ & $46 \cdot 65$ \\
\hline $\begin{array}{l}\text { Warrington Recognition Memory Test } \\
(\text { Faces }) \\
(\max . \text { score }=50)\end{array}$ & $41 \cdot 82$ & $41 \cdot 76$ & $45 \cdot 47$ \\
\hline $\begin{array}{l}\text { FACES LINE-UP } \\
\text { (a) familiarity decision } \\
(\max . \text { score }=40)\end{array}$ & $37 \cdot 88$ & $35 \cdot 82$ & $38 \cdot 00$ \\
\hline $\begin{array}{l}\text { (b) occupation decision } \\
\text { (max. score }=20 \text { ) }\end{array}$ & $17 \cdot 88$ & $18 \cdot 42$ & $19 \cdot 62$ \\
\hline $\begin{array}{l}\text { (c) naming } \\
(\max . \text { score }=20)\end{array}$ & $13 \cdot 82$ & $16 \cdot 59$ & $18 \cdot 18$ \\
\hline
\end{tabular}

significantly worse than the right TLE group on reading relatively uncommon words with irregular spellings.

Test for the Reception of Grammar. The overall effect of groups was significant $(\mathrm{F}=5 \cdot 19, \mathrm{df}=2,48, p<0 \cdot 001)$. Post-hoc Newman-Keuls tests $(p<0.05)$ showed that the left and right TLE groups both performed worse than the control subjects. Although the direction of the difference between the means of the two TLE groups is in the predicted direction of worse performance by the left TLE group, the difference on syntactic performance was not significant.

Warrington Recognition Memory Test: Words. There was no significant difference between the three groups on recognition memory for words.

Warrington Recognition Memory Test: Faces. The overall effect of groups was significant $(\mathrm{F}=5 \cdot 18, \mathrm{df}=2,48, p<0 \cdot 001)$. Post-hoc Newman-Keuls tests $(p<0.05)$ showed that the left and right TLE groups both performed worse than the control subjects, but that the two TLE groups did not differ significantly on recognition memory for unfamiliar faces. 
Faces line-up. The familiarity decision component of the faces line-up requires subjects to discriminate 20 famous from 20 unfamiliar faces. The effect of groups on familiarity decision accuracy was significant $(F=4.02$, $\mathrm{df}=2,48, p<0 \cdot 05)$. Post hoc Newman-Keuls tests showed that the right TLE group performed significantly worse than both the left TLE group and the control group who did not differ significantly on familiarity decision accuracy.

The occupation decision component of the faces line-up requires subjects to state the occupation of those people whose faces are recognized as familiar. The effect of subject groups on this component of the line-up was not significant $(\mathrm{F}=1 \cdot 83, \mathrm{df}=2,48$, n.s. $)$.

Finally, the naming component of the line-up requires subjects to name those people whose faces are recognized as familiar. The effect of subject groups on this component of the line-up was significant $(\mathrm{F}=7 \cdot 19, \mathrm{df}=2,48$, $p<0 \cdot 005)$. Post-hoc Newman-Keuls tests $(p<0.05)$ showed that the left TLE group performed significantly worse than both the right TLE group and the Control group who did not differ significantly on naming familiar faces.

\section{Discussion}

The left TLE group performed worse than both the right TLE group and the control group on the Graded Naming Test, the National Adult Reading Test and on naming of famous faces. In contrast, the right TLE group performed significantly worse than the left TLE group and the controls on the familiarity decision component of the faces line-up. This pattern is broadly as predicted.

On the Test for the Reception of Grammar, the two TLE groups did not differ significantly, though the trend was in the direction of worse performance by the left TLE group. The Warrington Recognition Memory Test for words did not reveal a difference between TLE patients and controls. This may reflect an insensitivity of the test to the levels of impairment displayed by patients with stable TLE. We note, however, that normal performance in TLE patients on tests of verbal recognition memory has also been reported by Hermann et al. (1987). Verbal memory deficits in left-sided TLE are clearest where the task involves a retrieval or recall component, and it is possible that focal temporal lobe epilepsy has more of an effect on retrieval of information from memory than on recognition memory performance. The left and right TLE groups were both equally impaired on the Warrington Recognition Memory Test for faces. Milner (1968) found an impairment of recognition memory for unfamiliar faces in right as compared with left temporal lobectomy patients, though the lack of a normal control group in that study means that we cannot tell whether the performance of the left temporal lobectomy group was fully normal. The failure to find a difference between left and right TLE groups on recognition memory for faces in the present study may again reflect a relative insensitivity of the test to the degrees of impairment shown by patients with TLE.

The pattern of results on the Faces Line-up test was as predicted. The 
right TLE group were significantly impaired on the familiarity decision component of the line-up, with the left TLE group performing at normal levels. Inspection of the data suggested that the deficit was primarily due to the right TLE patients claiming to recognize some of the non-famous faces (false positive errors) rather than failing to recognize the famous faces as familiar. The mean familiarity decision scores for correct positive responses to famous faces were right TLE 19.2, left TLE 19.6, controls 19.8, while the mean scores for the non-famous faces were right TLE 16.6, left TLE 18.6, controls $17 \cdot 8$. This pattern is different from that shown by the right temporal lobectomy patient KS reported by A. Ellis et al. (1989) who made virtually no false positive errors to non-famous faces but failed to recognize many famous faces as familiar. While this difference remains to be explained, the importance of the right temporal lobe in recognizing familiar faces is further substantiated by the results of the present study.

No difference was observed between the groups on the provision of occupation information for the famous faces, but then there is as yet no firm evidence that semantic information about familiar people is lateralized (Ellis, 1983). On the name retrieval component of the faces line-up a crossover was observed such that the left TLE group were now impaired relative to the right TLE group and the controls who did not differ. This result echoes the findings of Warrington and James (1967) with temporal lobectomy patients where the right temporal lobectomy group made more identification errors to famous faces and the left group more naming errors.

Neurophysiological and neuropathological studies of TLE suggest several possible mechanisms that may account for the cognitive impairments observed in patients with TLE. Such patients do not form a homogeneous group as far as the aetiology of the epilepsy is concerned (Bruton, 1988). TLE has been shown to be associated with cell loss in the hippocampal formation, especially (but not exclusively) in patients with early onset seizures (Dam, 1980; Sagar and Oxbury, 1987). Although cell loss in the hippocampal formation might account for impaired verbal or visuo-spatial memory performance in TLE patients, tasks such as naming pictures, reading aloud irregular words and processing the syntax of sentences do not appear to depend upon the hippocampal formation and have not been reported as being impaired in amnesic patients with hippocampal damage. The pattern of results obtained in the present study points towards impaired cortical functioning in at least some patients with TLE.

For certain patients with TLE the epileptogenic focus may be a cortical lesion (Bruton, 1988). It is also possible that loss of cell numbers is not confined to the hippocampal formation but may extend to cortical areas (Falconer et al., 1964). There are, however, other possible explanations for cortical deficits in TLE. Subclinical electrical seizures may be associated in some patients with frequent but transient cognitive impairment (TCI). Such transient impairments have been shown to depend on the lateralization of the discharge (Binnie et al., 1987). It is possible that frequent TCIs throughout the life of an epileptic patient could retard normal cognitive 
development, or alternatively that some errors in the testing session occurred during such subclinical seizures.

Another possible explanation for impaired cortical functioning in TLE patients comes from research employing the technique of xenon enhanced $\mathrm{X}$-ray computed tomography (XeCT). Such research has shown that interictal blood flow to the epileptogenic lobe may be reduced by up to $30 \%$ compared with the unaffected side (Fish et al., 1987). Reductions of that extent are very likely to cause suboptimal performance on cognitive tasks that rely on the affected cortical areas. Further work will be necessary before the relative contributions of these various factors can be teased apart.

The results of the present study suggest that the effects of focal TLE may be maximal on the side of the focus but may not be entirely limited to that side. The right TLE group performed as well as the non-epileptic controls on famous face naming, but worse than the controls on the other language tests. This pattern may be a result of secondary generalization of seizures causing damage to the contralateral hemisphere, though Valmier et al. (1987) have also shown reduced blood flow in areas contralateral to the epileptogenic focus as compared with the corresponding areas of the brains of nonepileptic controls.

\section{Acknowledgements}

We thank Dr E. Spokes for referring patients to us, and the patients themselves for their co-operation.

\section{References}

Berlin, C. I., Lowe-Bell, S. S., Jannetta, P.J. and Kline, D. G. (1972). Central auditory deficits after temporal lobectomy. Archives of Otolaryngology, 96, 4-10.

Binnie, G. D., Kasteleijn-Nolst Triente, D. G. A., Smit, A. M. and Wilkins, A. J. (1987). Interactions of epileptiform EEG discharges and cognition. Epilepsy Review, 1, 239-245.

Bishop, D. V. M. (1982). "Test for the Reception of Grammar". Medical Research Council, London.

Bruton, C. J. (1988). "The Neuropathology of Temporal Lobe Epilepsy". Oxford University Press, Oxford.

Dam, W. M. (1980). Epilepsy and neuron loss in the hippocampus. Epilepsia, 21, 617-29.

Delaney, R. C., Rosen, A. J., Mattson, R. H. and Novelly, R. A. (1980). Memory function in focal epilepsy: A comparison of non-surgical, unilateral temporal lobe and frontal samples. Cortex, 16, 103-117.

Ellis, A. W., Young, A. W. and Critchley, E. M. R. (1989). Loss of memory for people following temporal lobe damage. Brain, 112, 1469-1483.

Ellis, H. D. (1983). The role of the right hemisphere in face perception. In "Functions of the Right Cerebral Hemisphere" (Ed. A. W. Young). Academic Press, London.

Falconer, M. A., Serefetinides, E. A. and Corsellis, J. A. N. (1964). Aetiology and pathogenesis of temporal lobe epilepsy. Archives of Neurology, 19, 233 240.

Fedio, P. and Mirsky, A.F. (1969). Selective intellectual deficits in children with temporal lobe or centrencephalic epilepsy. Neuropsychologia, 7, 287-300.

Fish, D. R., Lewis, T. T., Brooks, D. J., Zilkha, E., Wise, R. J. S. and Kendall, B. E. (1987). Regional cerebral blood flow of patients with focal epilepsy studied using xenon 
enhanced CT brain scanning. Fournal of Neurology, Neurosurgery and Psychiatry, 50, 1584 1588.

Hermann, B. P., Wyler, A. R., Richey, E. T. and Rea, J. M. (1987). Memory function and verbal learning ability in patients with complex partial seizures of temporal lobe origin. Epilepsia, 28, 547-554.

Kimura, D. (1963). Right temporal lobe damage. Archives of Neurology, 8, 264-271.

Lavadas, E., Umilta, C. and Provinciali, C. (1979). Hemisphere-dependent cognitive performances in epileptic patients. Epilepsia, 20, 493-502.

Mayeux, R., Brandt, J., Rosen, J. and Benson, D. F. (1980). Interictal memory and language impairment in temporal lobe epilepsy. Neurology, 30, 120-125.

McKenna, P. and Warrington, E. K. (1983). "Graded Naming Test". NFER-Nelson, Windsor, England.

Milner, B. (1958). Psychological defects produced by temporal lobe excisions. Research Publications of the Association for Research in Nervous and Mental Diseases, 36, 244-257.

Milner, B. (1968). Visual recognition and recall after right temporal-lobe excision in man. Neuropsychologia, 6, 191-209.

Mungas, D., Ehlers, C., Walton, N. and McCutchen, C. B. (1985). Verbal learning differences in epileptic patients with left and right temporal lobe foci. Epilepsia, 26, 340345.

Nelson, H. E. (1982). "National Adult Reading Test (NART)". NFER-Nelson, Windsor, England.

Petrides, M. and Milner, B. (1982). Deficits on subject-ordered tasks after frontal- and temporal-lobe lesions in man. Neuropsychologia, 20, 249-262.

Rhodes, G. (1986). Lateralized processes in face recognition. British Journal of Psychology, 76, 249-271.

Sagar, H.J. and Oxbury, J. M. (1987). Hippocampal neuron loss in temporal lobe epilepsy: Correlation with early childhood convulsions. Annals of Neurology, 22, 334-340.

Sergent, J. and Villemure, J-G (1989). Prosopagnosia in a right hemispherectomized patient. Brain, 112, 975-995.

Valmier, J., Touchon, J., Paures, P., Zanca, M. and Baldy-Moulinier, M. (1987). Correlations between cerebral blood flow variations and clinical parameters in temporal lobe epilepsy: an interictal study. Fournal of Neurology, Neurosurgery and Psychiatry, 50, 13061311.

Warrington, E. K. (1984). "Recognition Memory Test". NFER-Nelson, Windsor, England.

Warrington, E. H. and James, M. (1967). An experimental investigation of facial recognition in patients with unilateral cerebral lesions. Cortex, 3, 317-326. 


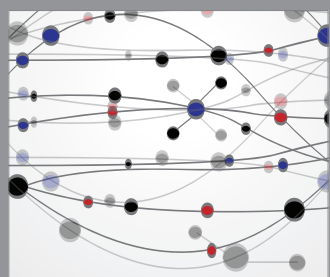

The Scientific World Journal
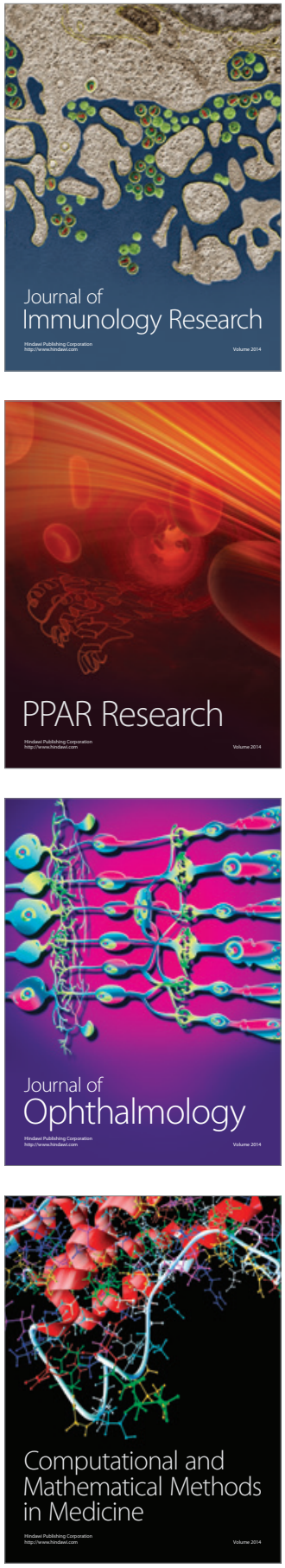

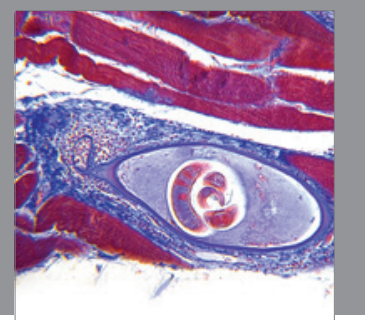

Gastroenterology

Research and Practice
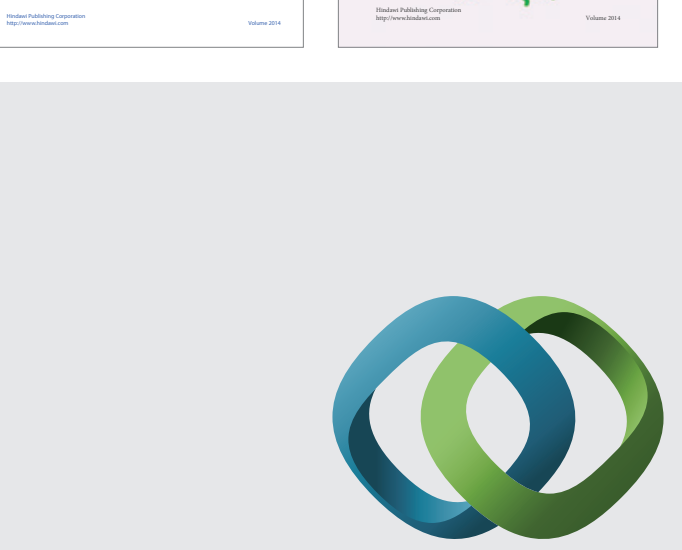

\section{Hindawi}

Submit your manuscripts at

http://www.hindawi.com
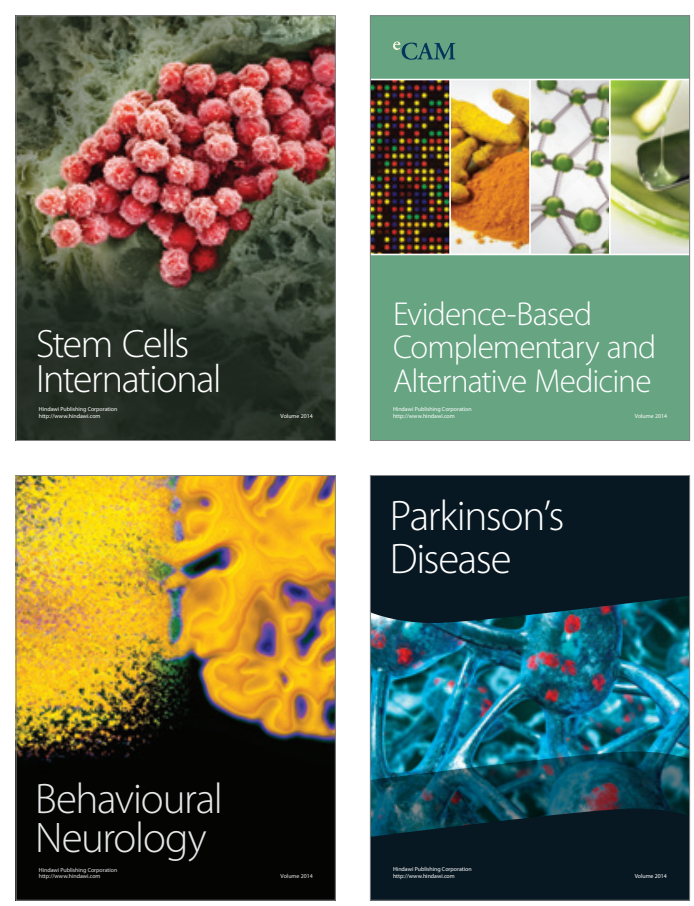

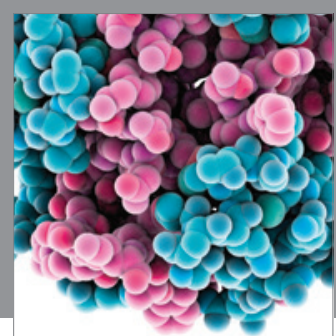

Journal of
Diabetes Research

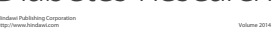

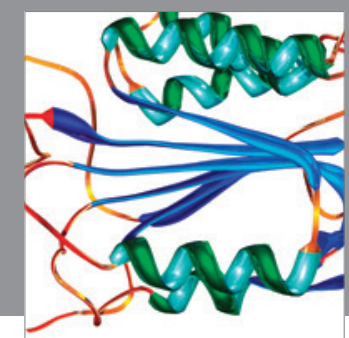

Disease Markers
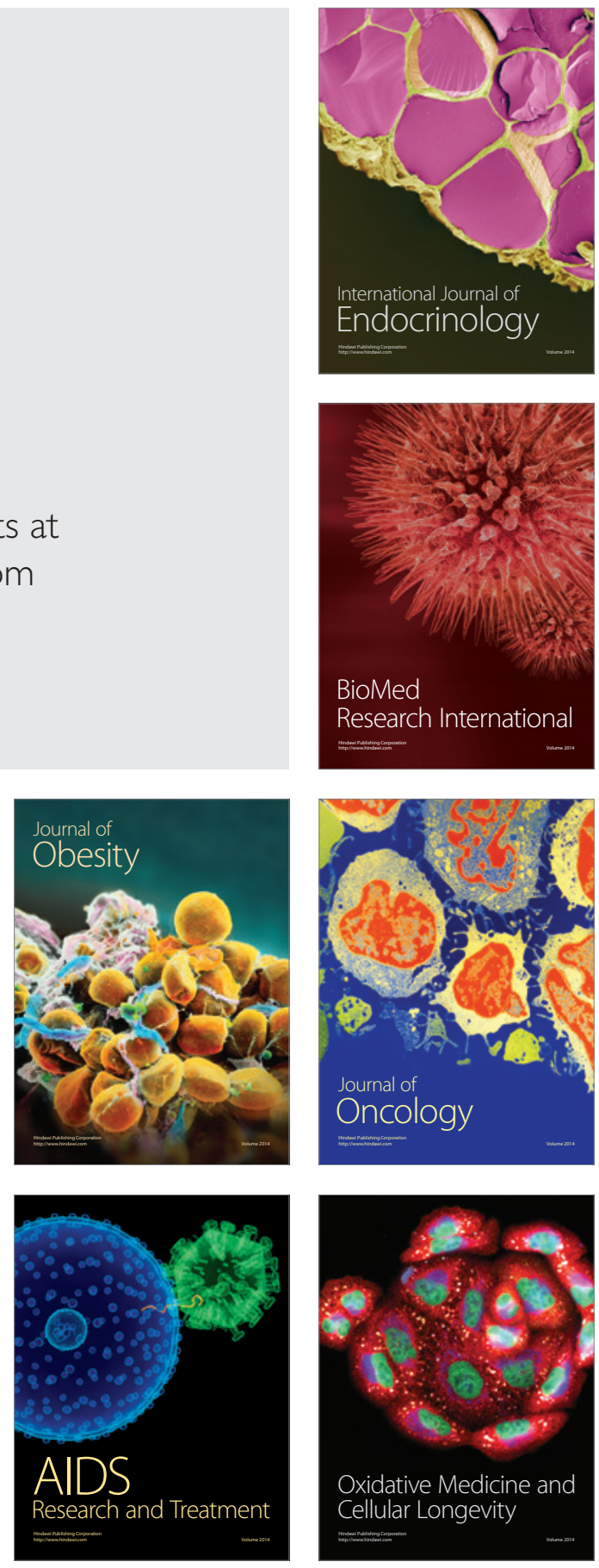